\title{
Die grosse Inschrift von Petra.
}

Von T7. Nöldeke.

Im Sept.-October-Heft des Fourn. as. I 896 hat der Altmeister der semitischen Epigraphik, Marquis DE VogüÉ die einst von A. H. FrAzER gemachte Abzeichnung der einzigen grossen nabatäischen Inschrift von Petra reproduciert und mit Uebersetzung und Erklärung versehn. Schon im Nov.-Dec.-Heft des Journals war er im Stande, nach einem vom $P$. LAGRANGE gemachten vorzüglichen $\mathrm{Ab}$ klatsch die Inschrift ganz genau herauszugeben und seine Uebersetzung und Erklärung $z u$ berichtigen. Eine etwas verkürzte Wiederholung dieses Artikels giebt er nun als Anhang $z u$ dem sehr lehrreichen und anziehenden Reisebericht des P. Lagrange im April-Heft der Revue biblique 1897. ${ }^{\mathrm{D}}$ ) Inzwischen hat mir BRÜnNow von Kerak aus eine kleine Copie derselben Inschrift geschickt. Sie beruht nur auf einer mit Hülfe eines Opernguckers gemachten Handzeichnung, denn er hatte keine Leiter zur Hand, um die hoch über dem Boden befindliche Inschrift abzuklatschen; sie ist aber so genau, dass sie durchweg mit DE VoGÜE's Facsimile übereinstimmt und im Nothfall den Abklatsch ersetzen könnte. $\mathrm{Da}$ in den uns vorliegenden Abzeichnungen jeder Buchstabe deutlich lesbar ist, so wäre es überflüssig, noch einmal ein Facsimile zu geben, und ich begnüge mich daher mit der Transscription.

I) Ich verdanke den Besitz dieses Artikels der Freundlichleit DE VoGüÉ's. Zeitschr. f. Assyriologie, XII. 
Th. Nöldeke

$$
\begin{aligned}
& \text { I קבריא רנה וצריחא רבא רי בה מנוא } \\
& \text { וצריחא ועירא ידי גוא מנה רי רי וצריח } \\
& \text { בה בתי מקבריץ עבירת גוחין } \\
& 2 \text { וברבא יו קרמיהם וערבותא }
\end{aligned}
$$

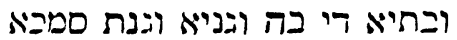

$$
\begin{aligned}
& \text { ובארות מיא וצהותא וטורי"א }
\end{aligned}
$$

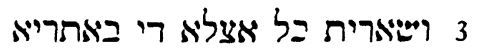

$$
\begin{aligned}
& \text { אלה חרם וחר: רושרא יאלה }
\end{aligned}
$$

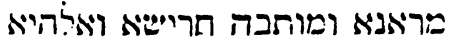

$$
\begin{aligned}
& \text { = } \\
& 4
\end{aligned}
$$

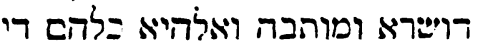

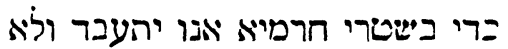

$$
\begin{aligned}
& \text { יתישניא }
\end{aligned}
$$

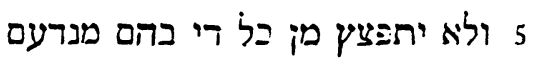

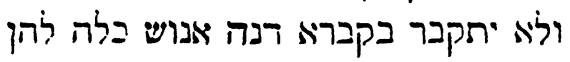

$$
\begin{aligned}
& \text { מן די בהיב לה תניא מקבר ביטטרי } \\
& \text { חרמיזא יאנו ער עלם יחיב יד }
\end{aligned}
$$

Mit starker Benutzung der Uebersetzung DE VoGüE's übertrage ich möglichst wörtlich:

I Dies Grabdenkmal und die grosse Grabkammer darin und die kleine Grabkammer innerhalb derselben, worin die Grabstätten sind, die aus loculi ${ }^{\top}$ ) bestehn,

2 und die Ringmauer(?) vor ihnen, und die Säulenhallen(???) und die Häuser darin und die Gärten und der Garten zum Gelage( $\because$ ) und die Wasserbrunnen und die dürren Stellen und die Berge

3 und aller andre Grund und Boden(?) an diesen Orten sind als der heilige, unentweihbare Boden des

I) In den Felsen gegrabene Hohlräume, die das eigentliche Grab bilden. Wörtlich »Grabstätten, Loculi-IVerk«. 
Dhūšarā, des Gottes unsers Herrn, und seines . . . . . . Rathes und aller Götter

4 (verzeichnet) in Schriftstücken über heilige Stätten, so wie es darin steht. So ist nun das Gebot des Dhūšarā und seines Rathes und aller Götter, dass, wie es in jenen Schriftstücken über die heiligen Stätten steht, verfahren werde und nicht verändert

5 noch abgenommen werde irgend etwas von allem, was in ihnen steht, und nicht begraben werde in diesem Grabdenkmal irgend einer, ausgenommen einer, für den die Bewilligung eines Grabes in jenen Schriftstücken übër die heiligen Stätten geschrieben ist, auf ewig.

Ich wiederhole hier nicht, was schon DE VoGüE zur Erklärung der Inschrift gesagt hat, gebe aber einige Bemerkungen zur Ergänzung und event. zur Berichtigung seines Commentars.

I אוl. Man beachte die Schreibung mit $N$ wie Dan. 3, $6,11,15,25,26.4,7.7,15$. Sie ist sicher etymologisch be-

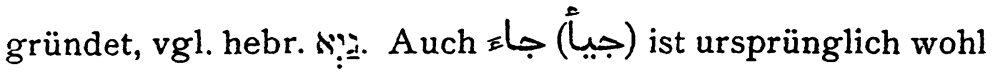

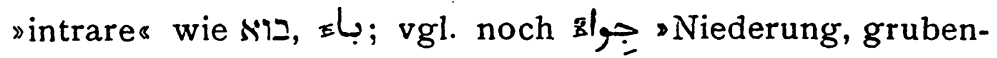
förmige Vertiefung «. Sonst auch im Nab. (Puteoli) und Palmyr. (Zolltarif II, 3, 7. II, 3, 47) schon is.

ist nicht "les demeures de ceux qui sont ensevelis«. מקברין ist kein Partic., sondern Substantiv, Plur.

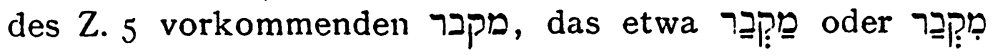
zu sprechen sein mag. Im Syrischen sagt man die Nabatäer setzen beide Glieder in den Plural.

2 קדמיהם. In der Transscription bei $D$. V. ist beidemal im Druck das' aus Versehen ausgefallen.

$\mathrm{Da}$ wir unter id nach D. V.'s richtiger Bemerkung nur ganz bescheidene Anlagen zu verstehn haben, so ist kein Grund, das folgende הג hiervon zu trennen und $z \mathfrak{u}$ 


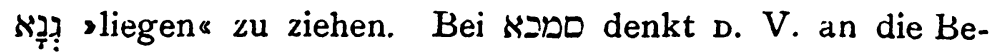

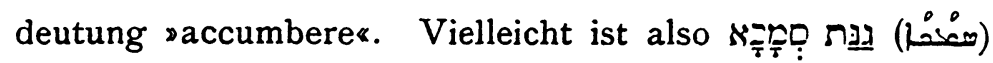
eine Gartenanlage, in welcher man sich $z u$ einem Todtenfest lagerte.

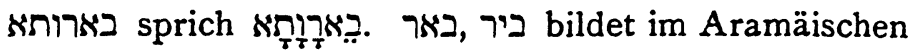
seinen Plural gewöhnlich mit Anhängung der männlichen Endung (כוj) u. s. w.), aber (bēräwän) im Fragmententargum Gen. 14, 10 und בארון im samarit. Targ. eb. Dazu stimmt das späthebr. ביראות und im Grunde schon das althebr. בְִִּרוֹת

Das Nebeneinander von צהותא וטוריא macht meines Erachtens die Uebersetzung: »die dürren (eigentlich sdurstigen \&) Stellen und die Berge " ganz sicher. Zum heiligen Bezirk des Grabmals gehörten ausser den cultivierten Stellen noch ein grösseres wasserloses Gebiet.

3 אצליא ist schwerlich das hebr. das ohne ein Pronominalsuffix nicht wohl denkbar ist. Vielleicht dart man darin das arab. أصقار sehen in der Bedeutung von

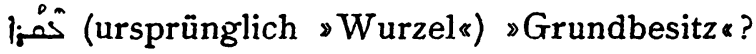

חרם וחרג nost nehme ich als Nomina. engung, Verbot, Verbotenes», entspricht also ziemlich dem حَرَام Oَم oder. Die beiden Nomina sind nach meiner Ansicht so eng verbunden, dass sie einen gemeinsamen Genitiv regieren können. Solche Verbindungen (in denen also das erste Glied im St. cstr. ohne unmittelbar folgenden Genitiv steht) sind im Altarabischen sehr selten, im Syrischen noch seltener, ${ }^{\mathrm{I}}$ ) im modernen Arabisch aber beliebt.

מותבה nimmt D. V. hier wie Hegr 3, 4 als Namen eines Gottes. Bedenklich ist da schon die Schreibung mit $\pi$,

I) S. die Verweisungen bei FineISCaER, Kleinere Schriften 2, 624. Ich könnte noch einige wenige classische Beispiele hinzufügen. Fürs Syrische s. meine Grammatik $§ 208$ A am Ende. 
bedenklich ferner, dass das folgende חריש:, das dann auch ein Gottesname wäre, kein I vor sich hat. Ich bin geneigt, nach einem Vorschlage meines Freundes LandaUEk

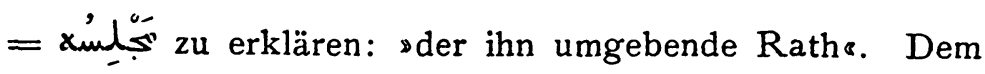
monarchisch regierten Volke der Nabatäer lag der Geחרי"שה . ist dann ein Epitheton, dessen Fehlen in der folgenden Zeile nicht befremden kann. Ueber die Bedeutung von חרישא sind mir allerlei Vermuthungen in den Sinn gekommen, aber da keine von ihnen besonders wahrscheinlich ist, so überlasse ich dafür Andern das Feld.

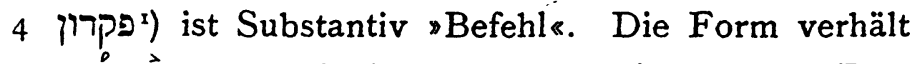

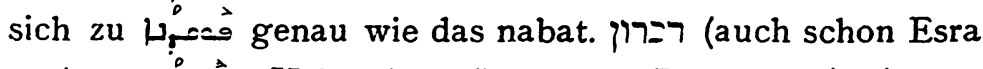

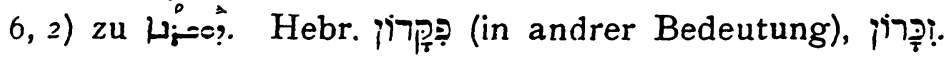

אנו las ich gleich hier und Z. 5 nach BRünnow's Copie, und so verbessert auch D. V. jetzt (in der Rev. bibl.) seine frühere Lesung אלו. Das Wort heisst nicht shi«, sondern »illiø, denn das Archiv muss an einem andern Ort ge-

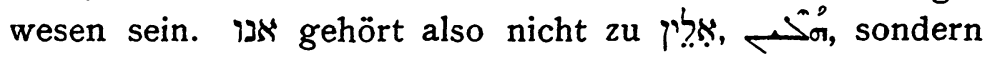

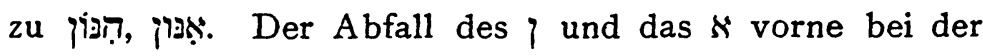
stark demonstrativen Bedeutung sind aber sehr auffallend.

תשנא. In diesem einzigen Worte nehme ich einen Buchstaben anders als D. V., der יתשלא liest. Mir steht das $\mathrm{J}$ vollkommen fest. Auch für den Sinn passt es allein, vgl. Esra 6, I1; Dan. 6, 9, 18. Die Eigenheit dieses Dialects, allein unter allen semitischen Sprachen bei den Reflexivformen das $\Omega$ vor dem anlautenden $Z$ ischlaut zu lassen, kennen wir schon aus יתזבן Hegr I1, 4; מתזבני (palmyr.) Zolltarif II, 3, 33. Denn dass dies alles Ettaphal-Formen seien, ist unwahrscheinlich.

5 יתפצ. Der ungefähre Sinn ist durch den Zusammen-

I) Bei diesem Worte allein finde ich ein kleines Versehen in BRüNNow's Copie: er hat da בפקרוו. 


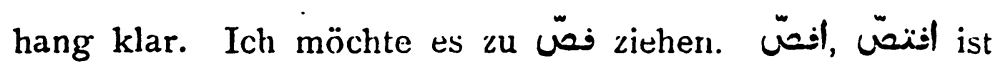
sabtrennen «, dazu فَصَّ „Gelenk «. ${ }^{1}$ ) Vielleicht dazu $k_{5} \varepsilon$, Pl. $120,9 \cdot 152,7)=$ פ

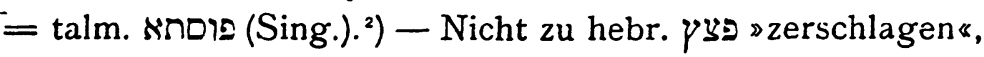
ות התפצ' zerschlagen werden « (vielleicht als Piel, resp. Hith-

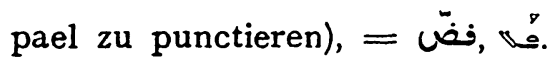

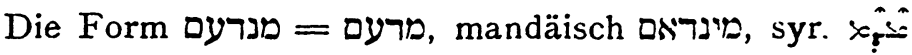
kann nicht befremden. Sie findet sich ausser in der Inschrift von Carpentras CIS II, I4 I noch vereinzelt einmal im Targum (s. Levy s. v.) und, was ganz besonders auffällt, ein einziges Mal selbst im Syrischen I Macc. 8, Ij im Cod. Ambros. (s. Ceriani's Ausgabe). Das $n$ auch im neusyr. mindĩ.

אנויש =ליה Genau so Hegr 12, 5, 6. 20, 4 und so da

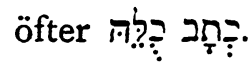

תנא darf man gewiss nicht mit D. V. von נחן ableiten; was wäre das für eine Form? Ich fasste תנن zunächst als ein Adverb, das sich zu verhielte wie bibl.-aram. ה

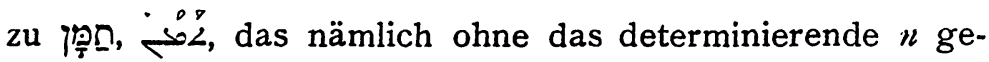
blieben wäre. Die Schwierigkeit ist nur, dass $\mathfrak{j}$ Lhiers

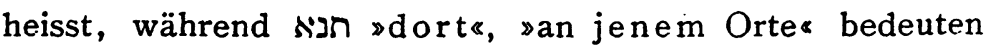
müsste. Da weiss ich nicht, ob wir hier nicht doch am Ende eine Form des Wortes haben, das im Späthebr. תני" תני geschrieben wird und von dem im Targum der

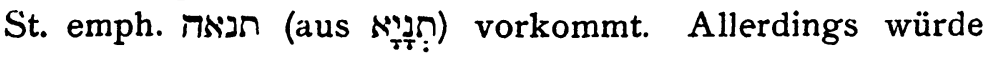

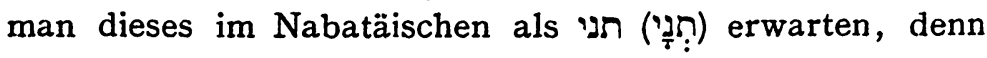
der Auslaut ist ohne $Z_{\text {weifel }} \bar{a} i$, nicht $a i$ (das in $\aleph_{-}$zu-

1) فََّّ "Siegelstein“ gehört kaum dazu (

2) Davon wohl wieder ganz verschieden $\mid L_{5} \hat{\theta}$, $\mid \Delta n \hat{e}$, , 
sammengezogen sein könnte). Aber hier ist vielleicht eine Nebenform, wie ja das Syrische mit der alten Fem.-En-

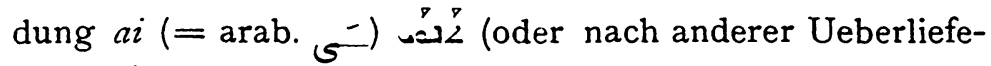
rung ئن hat, dem eine kürzere Bildung zu Grunde liegt.

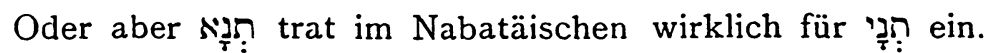
Die Bedeutung: „Uebereinkommen, Verabredung, Pact« würde passen.

Strassburg i. E. Mai 1897. 